Review Paper:

\title{
A Practical Approach to the Nutritional Management of Mechanically Ventilated Children: A Review
}

\author{
Fatemeh Roudi ${ }^{1}$, Zahra Dehnavi ${ }^{1}$, Gholamreza Khademi ${ }^{*}$
}

1. Department of Nutrition, Faculty of Medicine, Mashhad University of Medical Sciences, Mashhad, Iran. 2. Department of Pediatrics, Faculty of Medicine, Mashhad University of Medical Sciences, Mashhad, Iran.

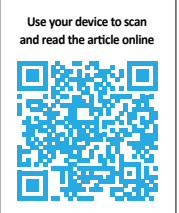

Citation Roudi F, Dehnavi Z, Khademi G. A Practical Approach to the Nutritional Management of Mechanically Ventilated Chidren: A Review. Journal of Pediatrics Review. 2021; 9(2):115-126. http://dx.doi.org/10.32598/jpr.9.2.919.1

doi 'http://dx.doi.org/10.32598/jpr.9.2.919.1

Article info:

Received: 16 Jul 2020

First Revision: 10 Aug 2020

Accepted: 22 Oct 2020

Published: 01 April 2021
Keywords:

Critically ill children, Mechanically ventilated children, Nutritional management

\begin{abstract}
A B S TR A C T
Context: Malnutrition is associated with a longer duration of mechanical ventilation and an increased risk of healthcare-acquired infections in critically ill children who are mechanically ventilated.

Objectives: Therefore, nutritional therapy plays a critical role in the initiation and duration of mechanical ventilation and clinical outcomes in such patients.

Data Sources: This review was conducted by searching the Web of Science, Scopus, Embase, and Medline databases. A combination of related mesh terms and keywords was used to find the relevant articles. Finally, we screened search results through titles and abstracts and related articles were enrolled in the review process. We tried to address all aspects of nutritional management of mechanically ventilated critically ill children.

Results: Energy demand in mechanically ventilated children is a controversial issue and Indirect Calorimetry (IC) is the recommended method to measure resting energy expenditure; however, in the absence of IC, predictive equations may be used. A minimum protein intake of $1.5 \mathrm{~g} / \mathrm{kg} /$ day and a balanced diet in other macronutrients ratio, including carbohydrates and lipids could be appropriate for mechanically ventilated children. However, the administration of major substrates should be based upon the patient's metabolism regarding the nature and phase of the illness. Moreover, individualized nutritional supplementation is among the treatment strategies in these children.
\end{abstract}

Conclusions: The optimum individualized nutrition support of mechanically ventilated children is considered a major therapeutic strategy and an essential aspect of their medical management. Further large population-based studies are required to provide appropriate feeding protocols for preventing nutritional inadequacy in such patients.

* Corresponding Author:

Gholamreza Khademi, MD.

Address: Department of Pediatrics, Faculty of Medicine, Mashhad University of Medical Sciences, Mashhad, Iran.

Tel: +98 (915) 3173028

E-mail:khademigh@mums.ac.ir 


\section{Context}

ritical illnesses and mechanical ventilation are associated with anorexia, inability to oral intake, catabolism state, altered gut absorption, and malnutrition (undernutrition/overnutrition) $(1,2)$. The aforementioned issues predispose patients to poor clinical outcomes (including delayed wound healing, the loss of lean body mass, nutrition deficits, and prolonged recovery), as well as increased morbidity and mortality rates $(1,2)$. Particularly, critically ill mechanically ventilated children are at higher risks for malnutrition, compared to adults. This is because of their higher relative energy requirements and lower energy reserves $(3,4)$.

Malnutrition involves up to $30 \%-45 \%$ of children admitted to the Pediatric Intensive Care Unit (PICU); it is associated with prolonged mechanical ventilation and increased risk of healthcare-acquired infections (5-8). The nutritional status of critically ill pediatric patients upon their PICU admission time is considered as a major predictor of the initiation and duration of stay on mechanical ventilation, in addition to its related complications (9). The optimal nutrition support of such patients, particularly adequate protein and energy intake is associated with improved clinical outcomes and decreased mortality and morbidity rates in mechanically ventilated children $(7,10)$.

As per previous studies, critically ill mechanically ventilated children are considered as a nutritionally high-risk group; thus, the nutrition support of such patients is an essential therapeutic strategy in the PICU $(1,11)$. However, consistent and convincing evidence on various features of the nutrition support of critically ill mechanically ventilated children is scarce $(1,10)$. Therefore, this study was performed to describe the main aspects of nutritional management in mechanically ventilated PICU patients.

\section{Evidence Acquisition}

The current review aimed to provide updates on the different aspects of the nutrition support of critically ill mechanically ventilated pediatric patients. Accordingly, we searched the relevant publications in the Web of Science, Cochrane, National Library of Medicine's PubMed, Embase, and Scopus databases using the combination of keywords and MeSH terms, including "nutrition", "nutritional support", "nutrition therapy", "nutritional status", "critical illness", "critically ill children", "mechanically ventilated children", and "Pediatric Acute Respiratory Distress Syndrome (PARDS)". Relevant publications of all types were identified. We limited the search to English language articles published since January 15t, 2005.

All Search results were screened through abstracts and titles. Primarily, 1566 records were identified. Additionally, to ensure study identification, two researchers cross-checked the reference lists of the relevant search results. Secondly, 6 additional studies were retrieved. The duplicate records were also removed. For the quality assessment of the relevant search records, we used "the Cochrane Collaboration's tool for assessing the risk of bias in randomized trials" and "the risk of bias in observational studies of exposures" tools $(12,13)$.

Finally, disagreements were resolved through discussion in a focus group panel, including 3 clinical nutritionists and 2 pediatricians who were PICU subspecialists. After eligibility screening and quality assessment, 79 articles and guidelines were included in the review process.

\section{Results}

\section{Stepwise nutrition support}

Similar to all PICU patients, the nutritional management of mechanically ventilated children consisted of 3 main steps, including baseline nutritional assessment, intervention, and monitoring (14). A primary nutritional assessment and routine monitoring as well as a nutrition care program for all critically ill mechanically ventilated pediatric patients is of particular importance since they are a nutritionally high-risk group $(1,11,14)$. Anthropometric assessments, including body weight, height/ length, body mass index, and Mid-upper Arm Circumference (MAC) should be performed at the baseline and routinely with a preset schedule (15). Alterations in weight/MAC may be correlated with cumulative suboptimal protein and energy delivery during PICU stay (16). Further, the routine measurement of nitrogen balance should be performed in PICU patients to modify diet in negative nitrogen balance situations (15). Additionally, measuring prealbumin as a major indicator of visceral protein pool may be helpful for such patients. However, clinicians should interpret the prealbumin level per the patient's illness severity and inflammation status (15).

Finally, some further routine assessments, such as complete blood count, liver function test, lipid profile, blood glucose, C-reactive protein, phosphorus, magnesium, and calcium levels may be indicated according to the underlying disease and baseline nutritional status $(14,15)$. The key aspects of the nutritional management 
Table 1. Key aspects of the nutritional management of mechanically ventilated critically ill children

\begin{tabular}{|c|c|}
\hline Variables & Outcomes \\
\hline Nutritional assessment & $\begin{array}{l}\text { Anthropometric parameters } \\
\qquad \begin{array}{c}\text { MAC } \\
\text { Body weights } \\
\text { Height/lengths }\end{array} \\
\text { Pre-albumin } \\
\text { CRP } \\
\text { Possible potential laboratory abnormalities } \\
\text { Complete blood count } \\
\text { Glucose } \\
\text { Phosphorus } \\
\text { Lipid profile } \\
\text { AST } \\
\text { ALT } \\
\text { Direct bilirubin } \\
\text { GGT }\end{array}$ \\
\hline Energy requirement & $\begin{array}{l}\text { Indirect calorimetry; if possible } \\
\text { Achieving delivery of at least two-thirds of the prescribed daily energy requirement by the end of the first week }\end{array}$ \\
\hline Macronutrients requirements & $\begin{array}{l}\qquad \text { Protein intake of } \geq 1.5 \mathrm{~g} / \mathrm{kg} / \mathrm{d} \\
\text { Lipid and Carbohydrate intake: Based upon metabolism in the dependence of phase and nature of the acute illness }\end{array}$ \\
\hline Micronutrients requirements & $\begin{array}{l}\text { Routinely in RDAs amounts } \\
\text { Assessment of possible potential micronutrients deficiencies and treatment of documented deficiencies: } \\
\text { Vitamin B1 (Thiamine) } \\
\text { Vitamin B2 (Riboflavin) } \\
\text { Vitamin B6(Pyridoxine) } \\
\text { Vitamin A (Beta-carotene/Retinol) }\end{array}$ \\
\hline
\end{tabular}

Journal of Pediatrics Review

MAC: Mid-upper arm circumference; CRP: C-reactive protein; AST: Aspartate aminotransferase; ALT: Alanine amino transaminase; GGT: v-glutamyl transpeptidase; PICU: Pediatric Intensive Care Unit; RDA: Recommended Dietary Allowance.

of mechanically ventilated PICU patients are presented in Table 1.

\section{Mechanically ventilated children: nutrition support} route

Enteral nutrition (EN) is the preferred route of nutrition support for all critically ill children (including mechanically ventilated patients) with a functioning gastrointestinal tract (17). EN keeps regular bowel movements; therefore, it reduces bacterial translocation, decreases the production of toxic cytokines, prevents mucosal atrophy, and maintains the epithelial barrier integrity (18).

The prioritization of Early EN (EEN) is defined as initiating EN within 48-72 h of PICU admission. EEN may provide several beneficial effects, including better tolerance of EN, higher odds of adequate intake achievement, shorter hospital and PICU stay, and reduced morbidity and mortality rates (19-26). For example, a study explored 500 mechanically ventilated children; patients who received less than $1 / 3$ of the calorie goal during the first 10 days of PICU admission presented a higher mortality rate (7). Therefore, EEN should be initiated imme- diately after the hemodynamic stability in the absence of medical contraindication to EN (27). Delayed EN initiating is commonly detected in such patients, i.e. associated with inadequate nutrition support (28).

Furthermore, several factors can disrupt EN delivery in critically ill children. Feed intolerance, several situations of gastrointestinal tract dysfunctions, prolonged fasting periods before procedures, failure to reinstitute nutrient intake timely after procedures, mechanical issues with feeding tubes, and restricted fluid intake are the most frequent impediments to EN (29-31). These barriers to EN may decrease nutrient delivery and lead to poor clinical outcomes in mechanically ventilated pediatric patients. Therefore, minimizing the aforementioned barriers in the PICU is of particular importance.

If EN fails to meet nutritional requirements, supplemental/total Parenteral Nutrition (PN) should be used in mechanically ventilated PICU patients (17). Moreover, Van Puffelen et al. reported better outcomes of withholding PN in the first week of PICU admission, compared to initiating supplemental PN within the first 24 $h$, in their clinical trial (32). Therefore, it is recommend- 
Table 2. Nutrition support route in mechanically ventilated children

Recommendations
EN is the preferred mode of nutrient delivery unless it is contraindicated.
A stepwise algorithmic approach is recommended.
It is essential to select the best site and optimum method for EN delivery.
Continuous vs. intermittent gastric feeding: data are insufficient to make recommendations.
PN should be initiated if EN is contraindicated.
Supplemental PN should be initiated if EN is insufficient.

EN: Enteral Nutrition; PN: Parenteral Nutrition.

Journal of Pediatrics Review

ed that PN not be started within the first $24 \mathrm{~h}$ of PICU admission (15). Table 2 illustrates the nutrition support route-related recommendations.

\section{Energy, macronutrients, and micronutrients require- ments}

The accurate estimation of energy requirements is crucial to prevent the under/overfeeding of patients during critical illnesses. Accurately measured energy expenditure in adult and pediatric critically ill patients is of particular significance $(17,33,34)$.

According to previous studies, underfeeding contributes to nutritional deprivation, leading to poor clinical outcomes. For example, undernutrition-induced endogenous protein breakdown may lead to the loss of lean body mass (including the respiratory, cardiac, \& skeletal muscles) and immunosuppression; accordingly, it may predispose the patient to delayed ventilator support weaning, nosocomial infections acquisition, and delayed wound healing $(27,35)$. On the other hand, overfeeding provides some deleterious consequences, including electrolyte imbalance, increased carbon dioxide production, respiratory and cardiovascular systems overload, delayed ventilator support weaning, and increased duration of PICU stay $(15,36-38)$.

Metabolic state in mechanically ventilated critically ill children is unpredictable; some of them present with a hypermetabolic state and most of them demonstrate lower energy expenditure, compared to their healthy counterparts. This declined energy expenditure may be due to the sedation, non-functioning respiratory system, the transient absence of growth, and activity reduction. Therefore, energy requirement estimation would be difficult and complex $(39,40)$. Using predictive equations (i.e. World Health Organization/Schofield/Food Agriculture Organization/United Nations University equations) would be inaccurate and may under/overestimate the $\operatorname{REE}(17,41)$. According to the literature, Indirect Calo- rimetry (IC) is identified as the gold standard to provide an accurate bedside measurement of REE in critically ill children (41-43). Given the inaccuracy of estimating energy needs by predictive equations and negative outcomes of under and overfeeding, PICU nutritional guidelines emphasize accurate and personalized energy requirement measurement, using IC (17).

However, applying IC in most centers and PICUs is cumbersome, as IC is only available in $14 \%$ of PICUs (44). Therefore, in the absence of IC, various predictive equations can be employed to measure the REE in such patients (41).

Another study reported that REE in PICU patients can be measured using VCO2 values alone (REE=1/4 $5.5 * \mathrm{VCO} 2(\mathrm{~L} / \mathrm{min}) * 1440)$ (45). Ventilators can measure VCO2 (based on the instantaneous flow); thus, clinicians can calculate the REE from ventilator-derived $\mathrm{VCO} 2$ in mechanically ventilated children weighing $\geq 15 \mathrm{~kg}$ (46).

Following REE estimation, macronutrient administration, including carbohydrates, proteins, and lipids should be performed regarding the phase and nature of the patient's illness $(15,40)$.

The critical illness period is associated with an increased protein requirement due to the catabolic phase; this is developed to support the production of immune-related and acute-phase proteins, as well as tissue repair. For instance, protein requirements can be increased by $100 \%$ in severe sepsis, and by $25 \%$ even in mild stresses (47).

According to the studies performed in the mechanically ventilated adult population, protein intake is independently crucial for clinical outcomes improvement. Therefore, it should be considered as a separate nutritional goal by clinicians (1). Adequate protein delivery is associated with a shorter duration of mechanical ventilation, lower mortality rate, and higher 60-day survival, 
even in subjects with inadequate energy intake (48). PICU patients are a high-risk group for depleting protein reserves which may lead to increased morbidity and mortality rates $(7,49)$. Especially, mechanical ventilation exacerbates protein catabolism and may contribute to negative nitrogen balance $(50,51)$. Thus, meeting the protein requirements of critically ill, children especially the mechanically ventilated ones is critical. On the other hand, excessive protein intake should be avoided, because it can lead to some adverse clinical outcomes, such as azotemia, metabolic acidosis, and neurologic dysfunction $(52,53)$. The ASPEN guideline recommended that a minimum of $1.5 \mathrm{gr} / \mathrm{kg}$ of body weight $(\mathrm{kg} / \mathrm{day})$ of protein should be considered in the nutritional management of all critically ill pediatric patients (15). Particularly, the protein requirement for mechanically ventilated infants and young pediatric patients with critical illnesses is estimated to be $2.5-3 \mathrm{~g} / \mathrm{kg} / \mathrm{d}(54,55)$. Additionally, concurrent sufficient carbohydrate and lipid delivery increase protein synthesis and turnover $(56,57)$.

Marta Botran et al. demonstrated that the standard enteral diets provide insufficient amounts of protein for the majority of pediatric patients with critical illnesses. Moreover, using the enteral protein supplementations presents several desirable consequences, including improved biochemical parameters of protein metabolism, decreased protein hyper-catabolism, and improved recovery without producing any adverse effects in such patients (54). Similarly, this anabolic response was observed in critically ill children/infants who received high protein diets or protein supplementation in Keshen's (58) and Van Waardenburg's studies (59). These data emphasize the critical role of protein delivery in the successful nutritional management of PICU patients. However, there is inadequate evidence to support the routine administration of high amounts of protein in all categories of children with critical illnesses; an accurate assessment of protein status is required (60). Prealbumin and albumin plasma/serum concentrations are not reliable markers to assess the protein status. This is because they are affected by several factors, including trauma, renal or liver diseases, fluid status, inflammation, and infection (61). Thus, nitrogen balance measurement is more sensitive to the acute changes of protein status in pediatric patients who are critically ill (61). As protein requirements are provided, carbohydrates and lipids, as the sources of energy are required for protein synthesis and meeting total energy expenditure (62).

In children with ARDS, traditional feeds consist of $40 \%$ $50 \%$ carbohydrates and $<30 \%$ lipids. However, some studies evaluated different formulations with high lipid and low carbohydrate evaluated. As a result, it may be associated with decreased production of $\mathrm{CO} 2$, in comparison to higher carbohydrate formulations, contributing to lower mechanical ventilation and ICU stay days (63). However, Hasan M. et al. argued that a higher fat-to-carbohydrate ratio was not related to decreased mechanical ventilation duration and further ventilator-free days (64). According to the PICU guidelines, a balance of carbohydrates and lipid ratio, as well as providing enough energy is suggested for mechanically ventilated critically ill children (17). However, there is a lack of evidence in this field and further cohort and clinical trials are required.

Similar to all critically ill children, mechanically ventilated patients should receive the RDA amounts of micronutrients and routinely be assessed for potential deficiencies (17). Finally, children with critical illnesses are at a higher risk of vitamin deficiencies (including vitamin A(beta-carotene/retinol), vitamin B1(thiamine), vitamin B2(riboflavin), and vitamin B6(pyridoxine)) concerning their underlying disease, nutritional status upon the PICU admission time, and metabolic status $(65,66)$.

\section{Immunonutrition}

Most pediatric patients with critical illnesses are at increased risk of compromised immunity. Immunosuppression is associated with an increased risk of infection acquisition and susceptibility to early hyper-inflammation status $(67,68)$. Thereby, immunonutrition support for improving immune system function and regulating inflammatory responses may be beneficial in such patients (69). These substances/supplementations include several antioxidants, glutamine, arginine, vitamin D (ergocalciferol/cholecalciferol), omega-3 fatty acids, metoclopramide, zinc, and selenium (62, 70-75).

Administrating omega-3 fatty acids in critically ill children and particularly in PARDS may present several beneficial effects. Such advantages include up-regulating the production of pro-inflammatory eicosanoids, increasing the synthesis of anti-inflammatory lipid mediators (e.g., resolvins \& protectins), and reducing the chemotaxis (76). Moreover, omega-3 fatty acids may lead to decreased pro-inflammatory cytokines, reactive oxygen species, and the expression of adhesion molecules (76). The aforementioned effects may contribute to a decrease in leukocyte binding as well as the activation and significant reduction of inflammatory markers $(27,76)$. The results of a meta-analysis by Dushianthan A et al. demonstrated that omega-3 fatty acids had no beneficial effects on clinical outcomes in ARDS adult 
patients (77). However, Briassoulis $G$ et al. concluded that omega-3 fatty acids and glutamine supplementation positively impacted the lipid profile of critically ill children (78). However, they detected no effects of the aforementioned supplementation on the ventilator dependency time and mortality rate (78). Evidence for routine omega-3 fatty acids supplementation in critically ill ventilated children is limited; therefore, further studies are needed to investigate the exact indications of supplementation in this group.

Arginine is a conditionally essential amino acid with several critical roles in various metabolic processes in human health and even diseases. Such health conditions include the detoxification of ammonia in the urea cycle, the synthesis of creatine and polyamines, the regulation of immune function, the production of Nitric Oxide (NO), and the release of anabolic hormones (79-81).

Previous studies reported low arginine plasma concentrations in adults and children with critical illnesses (82). In critical illness states, inflammation is related to higher cortisol levels and lower insulin concentrations which contribute to alternations in plasma arginine level (83). In critically ill children with sepsis and burns, and increased arginine breakdown as well as unchanged de novo synthesis of arginine were reported; subsequently, they resulted in negative arginine balance in such situations. Thus, the increased breakdown of arginine was associated with the higher synthesis of NO and increased oxidation $(84,85)$. However, there is insufficient data on the possible beneficial effects of arginine in critically ill children. Therefore, further clinical trials are required to provide strong recommendations. Similar to arginine, glutamine is a conditionally essential amino acid that becomes crucial in some critical conditions, such as sepsis, major trauma, or surgery $(27,86,87)$.

Most critically ill patients, including the pediatric population, have low plasma glutamine concentrations, i.e. correlated with increased risk of multiple organ failure and mortality rate (88). Further studies are required concerning glutamine administration in mechanically ventilated critically ill children; however; this plasma glutamine depletion is the rationale for glutamine supplementation in PICU patients.

Vitamin $D$ is considered as an immunonutrient that crucially influences the immune system cell functions, such as macrophages, lymphocytes, epithelial and T-helper 2 cells (89). Vitamin D deficiency is a major predisposing factor for muscle loss, cardiovascular diseases, immune dysfunction, impaired glucose metabo- lism, and compromised pulmonary function (90-93). It is reported that $30 \%-70 \%$ of PICU patients suffer from vitamin D deficiency (94). Furthermore, vitamin D deficiency is associated with increased illness severity, vasopressor administration, and mechanical ventilation requirements in critically ill children (94). Moreover, vitamin $D$ insufficiency/deficiency may lead to an increased risk of respiratory infections acquisition (95).

Vitamin D deficiency is related to decreased vitamin $D$ receptor expression, contributing to impaired microorganism clearance and uncontrolled inflammation; subsequently, such conditions may lead to lung damage and impaired oxygenation (96). In a study on critically ill children, low vitamin D levels were associated with increased sepsis rate; however, there was no statistically significant association between vitamin $D$ concentrations and mortality rate, duration of PICU stay, and mechanical ventilation duration (97). Furthermore, Rippel C et al. documented that hypovitaminosis D was prevalent in PICU patients; it was associated with hypocalcemia and an increased necessity for calcium replacement particularly in the cardiac population (98). However, there was no association between vitamin D status and survival or PICU duration (98).

Finally, immunonutrition substances provide various potentially beneficial effects; however, some studies demonstrated that immunonutrition presents no beneficial effect on inflammatory and immune responses $(99,100)$. Thus, further clinical trials are required to find the exact indications, contraindications, and recommended dose of aforementioned supplementations in mechanically ventilated children with critical illnesses.

\section{Conclusion}

Mechanically ventilated critically ill children constitute a nutritionally high-risk group. Therefore, a reasonable stepwise nutrition care program is necessary for this respect. Optimum and individualized nutrition support of these children is considered a major therapeutic strategy.

IC is strongly recommended to calculate their energy requirement; however, in the absence of IC, predictive equations should be used. Administrating major substrates should be based on the patient's metabolism according to the phase of the illness. Immunonutrition substances present various potentially beneficial effects; however, further studies, especially randomized clinical trials are required to find the accurate indications of such supplementations. 


\section{Ethical Considerations}

\section{Compliance with ethical guidelines}

There were no ethical considerations to be considered in this research.

\section{Funding}

This research did not receive any grant from funding agencies in the public, commercial, or non-profit sectors.

\section{Authors' contributions}

All authors equally contributed to preparing this article.

\section{Conflicts of interest}

The authors declared no conflict of interest.

\section{References}

1. Allen K, Hoffman L. Enteral nutrition in the mechanically ventilated patient. Nutrition in Clinical Practice. 2019; 34(4):540-57. [DOI:10.1002/ncp.10242] [PMID]

2. McClave SA, Martindale RG, Vanek VW, McCarthy M, Roberts $P$, Taylor B, et al. Guidelines for the provision and assessment of nutrition support therapy in the adult critically ill patient: Society of Critical Care Medicine (SCCM) and American Society for Parenteral and Enteral Nutrition (A.S.P.E.N.). Journal of Parenteral and Enteral Nutrition. 2009; 33(3):277316. [DOI:10.1177/0148607109335234] [PMID]

3. Chwals WJ. Overfeeding the critically ill child: Fact or fantasy? New Horizons. 1994; 2(2):147-55. [PMID]

4. Klein S, Kinney J, Jeejeebhoy K, Alpers D, Hellerstein M, Murray $M$, et al. Nutrition support in clinical practice: Review of published data and recommendations for future research directions. Summary of a conference sponsored by the National Institutes of Health, American Society for Parenteral and Enteral Nutrition, and American Society for Clinical Nutrition. The American Journal of Clinical Nutrition. 1997; 66(3):683-706. [DOI:10.1093/ajcn/66.3.683] [PMID]

5. Prieto MB, Cid JL. Malnutrition in the critically ill child: The importance of enteral nutrition. International Journal of Environmental Research and Public Health. 2011; 8(11):4353-66. [DOI:10.3390/ijerph8114353] [PMID] [PMCID]

6. de Souza Menezes F, Leite HP, Koch Nogueira PC. Malnutrition as an independent predictor of clinical outcome in critically ill children. Nutrition. 2012; 28(3):267-70. [DOI:10.1016/j.nut.2011.05.015] [PMID]
7. Mehta NM, Bechard L, Cahill N, Wang M, Day A, Duggan $\mathrm{CP}$, et al. Nutritional practices and their relationship to clinical outcomes in critically ill children: An international multicenter Cohort study*. Critical Care Medicine. 2012; 40(7):2204-11. [DOI:10.1097/CCM.0b013e31824e18a8] [PMID] [PMCID]

8. de Mello MJ, de Albuquerque Mde F, Ximenes RA, Lacerda $H R$, Ferraz EJ, Byington R, et al. Factors associated with time to acquisition of bloodstream infection in a pediatric intensive care unit. Infection Control \& Hospital Epidemiology. 2010; 31(3):249-55. [DOI:10.1086/650450] [PMID]

9. Grippa RB, Silva PS, Barbosa E, Bresolin NL, Mehta NM, Moreno YM. Nutritional status as a predictor of duration of mechanical ventilation in critically ill children. Nutrition. 2017; 33:91-5 [DOI:10.1016/j.nut.2016.05.002] [PMID]

10. Briassoulis G, Zavras N, Hatzis T. Malnutrition, nutritional indices, and early enteral feeding in critically ill children. Nutrition. 2001; 17(7-8):548-57. [DOI:10.1016/S08999007(01)00578-0]

11. Joffe A, Anton N, Lequier L, Vandermeer B, Tjosvold L, Larsen $B$, et al. Nutritional support for critically ill children. The Cochrane database of systematic reviews. 2016; 2016(5):CD005144. [DOI:10.1002/14651858.CD005144. pub3] [PMID] [PMCID]

12. Bero L, Chartres N, Diong J, Fabbri A, Ghersi D, Lam J, et al. The risk of bias in observational studies of exposures (ROBINSE) tool: Concerns arising from application to observational studies of exposures. Systematic Reviews. 2018; 7(1):242. [DOI:10.1186/s13643-018-0915-2] [PMID] [PMCID]

13. Higgins JP, Altman DG, Gotzsche PC, Juni P, Moher D, Oxman $A D$, et al. The Cochrane collaboration's tool for assessing risk of bias in randomised trials. British Medical Journal. 2011 343:d5928. [DOI:10.1136/bmj.d5928] [PMID] [PMCID]

14. Khademi G, Imani B, Mehdizadeh A. Assessment, intervention, and monitoring: Stepwise nutritional management in pediatric intensive care units: A short review. Journal of Comprehensive Pediatrics. 2019; 10(1):e66474. [DOI:10.5812/compreped.66474]

15. Mehta NM, Skillman HE, Irving SY, Coss-Bu JA, Vermilyea $S$, Farrington EA, et al. Guidelines for the provision and assessment of nutrition support therapy in the pediatric critically ill patient: Society of critical care medicine and american society for parenteral and enteral nutrition. Journal of Parenteral and Enteral Nutrition. 2017; 41(5):706-42. [DOI:10.1177/0148607117711387] [PMID]

16. Hulst JM, van Goudoever JB, Zimmermann L, Hop WC, Albers MJ, Tibboel $D$, et al. The effect of cumulative energy and protein deficiency on anthropometric parameters in a pediatric ICU population. Clinical Nutrition. 2004; 23(6):1381-9. [DOI:10.1016/j.clnu.2004.05.006] [PMID]

17. Mehta NM, Compher C, Directors ASPENBo. A.S.P.E.N. Clinical Guidelines: Nutrition support of the critically ill child. Journal of Parenteral and Enteral Nutrition. 2009; 33(3):260-76. [DOI:10.1177/0148607109333114] [PMID] 
18. Fukatsu K, Zarzaur BL, Johnson CD, Lundberg AH, Wilcox $H G$, Kudsk KA. Enteral nutrition prevents remote organ injury and death after a gut ischemic insult. Annals of Surgery. 2001; 233(5):660-8. [DOI:10.1097/00000658200105000-00010] [PMID] [PMCID]

19. Haney A, Burritt E, Babbitt CJ. The impact of early enteral nutrition on pediatric acute respiratory failure. Clinical Nutrition ESPEN. 2018; 26:42-6. [DOI:10.1016/j.clnesp.2018.04.017] [PMID]

20. Khalid I, Doshi P, DiGiovine B. Early enteral nutrition and outcomes of critically ill patients treated with vasopressors and mechanical ventilation. American Journal of Critical Care. 2010; 19(3):261-8. [DOI:10.4037/ajcc2010197] [PMID]

21. Mikhailov TA, Kuhn EM, Manzi J, Christensen M, Collins $M$, Brown AM, et al. Early enteral nutrition is associated with lower mortality in critically ill children. Journal of Parenteral and Enteral Nutrition. 2014; 38(4):459-66. [DOI:10.1177/0148607113517903] [PMID]

22. Leroue MK, Good RJ, Skillman HE, Czaja AS. Enteral nutrition practices in critically ill children requiring noninvasive positive pressure ventilation. Pediatric Critical Care Medicine. 2017; 18(12):1093-8. [DOI:10.1097/ PCC.0000000000001302] [PMID]

23. Feng $\mathrm{Y}$, Ralls MW, Xiao W, Miyasaka E, Herman RS, Teitelbaum DH. Loss of enteral nutrition in a mouse model results in intestinal epithelial barrier dysfunction. Annals of the New York Academy of Sciences. 2012; 1258:71-7. [DOI:10.1111/j.1749-6632.2012.06572.x] [PMID] [PMCID]

24. Johnson CD, Kudsk KA, Fukatsu K, Renegar KB, Zarzaur $\mathrm{BL}$. Route of nutrition influences generation of antibodyforming cells and initial defense to an active viral infection in the upper respiratory tract. Annals of Surgery. 2003; 237(4):565-73. [DOI:10.1097/01.SLA.0000059991.89316. B8] [PMID] [PMCID]

25. Ohta K, Omura K, Hirano K, Kanehira E, Ishikawa N, Kato $Y$, et al. The effects of an additive small amount of a low residual diet against total parenteral nutrition-induced gut mucosal barrier. The American Journal of Surgery. 2003; 185(1):79-85. [DOI:10.1016/S0002-9610(02)01108-X]

26. Sacks GS, Kudsk KA. Maintaining mucosal immunity during parenteral feeding with surrogates to enteral nutrition. $\mathrm{Nu}$ trition in Clinical Practice . 2003; 18(6):483-8. [DOI:10.1177 /0115426503018006483] [PMID]

27. Iyer R, Bansal A. What do we know about optimal nutritional strategies in children with pediatric acute respiratory distress syndrome? Annals of Translational Medicine. 2019; 7(19):510. [DOI:10.21037/atm.2019.08.25] [PMID] [PMCID]

28. Keehn A, O'Brien C, Mazurak V, Brunet-Wood K, Joffe A, de Caen $A$, et al. Epidemiology of interruptions to nutrition support in critically ill children in the pediatric intensive care unit. Journal of Parenteral and Enteral Nutrition. 2015; 39(2):211-7. [DOI:10.1177/0148607113513800] [PMID]
29. Rogers EJ, Gilbertson HR, Heine RG, Henning R. Barriers to adequate nutrition in critically ill children. Nutrition. 2003; 19(10):865-8. [DOI:10.1016/S0899-9007(03)00170-9]

30. Mehta NM, McAleer D, Hamilton S, Naples E, Leavitt K, Mitchell $P$, et al. Challenges to optimal enteral nutrition in a multidisciplinary pediatric intensive care unit. Journal of Parenteral and Enteral Nutrition. 2010; 34(1):38-45. [DOI:10.1177/0148607109348065] [PMID] [PMCID]

31. Meyer R, Harrison S, Sargent S, Ramnarayan P, Habibi $P$, Labadarios $D$. The impact of enteral feeding protocols on nutritional support in critically ill children. Journal of human nutrition and dietetics. 2009; 22(5):428-36. [DOI:10.1111/ j.1365-277X.2009.00994.x] [PMID]

32. van Puffelen E, Vanhorebeek I, Joosten KFM, Wouters PJ, Van den Berghe G, Verbruggen SCAT. Early versus late parenteral nutrition in critically ill, term neonates: A preplanned secondary subgroup analysis of the PEPaNIC multicentre, randomised controlled trial. The Lancet Child \& Adolescent Health. 2018; 2(7):505-15. [DOI:10.1016/ S2352-4642(18)30131-7]

33. Mehta NM, Bechard LJ, Leavitt K, Duggan C. Severe weight loss and hypermetabolic paroxysmal dysautonomia following hypoxic ischemic brain injury: The role of indirect calorimetry in the intensive care unit. Journal of Parenteral and Enteral Nutrition. 2008; 32(3):281-4. [DOI:10.1177/0148607108316196] [PMID]

34. Martindale RG, McClave SA, Vanek VW, McCarthy M, Roberts $\mathrm{P}$, Taylor B, et al. Guidelines for the provision and assessment of nutrition support therapy in the adult critically ill patient: Society of Critical Care Medicine and American Society for Parenteral and Enteral Nutrition: Executive Summary. Critical Care Medicine. 2009; 37(5):175761. [DOI:10.1097/CCM.0b013e3181a40116] [PMID]

35. Krzak A, Pleva M, Napolitano LM. Nutrition therapy for ALI and ARDS. Critical Care Clinics. 2011; 27(3):647-59. [DOI:10.1016/j.ccc.2011.05.004] [PMID]

36. MacIntyre NR, Cook DJ, Ely EW, Jr., Epstein SK, Fink JB, Heffner JE, et al. Evidence-based guidelines for weaning and discontinuing ventilatory support: A collective task force facilitated by the American College of Chest Physicians; the American Association for Respiratory Care; and the American College of Critical Care Medicine. Chest. 2001; 120(suppl 6):375S-95S. [DOI:10.1378/chest.120.6_suppl.375S] [PMID]

37. Askanazi J. Respiratory changes induced by the large glucose loads of total parenteral nutrition. JAMA: The Journal of the American Medical Association. 1980; 243(14):1444-7. [DOI:10.1001/jama.1980.03300400028023] [PMID]

38. de Betue $C T$, van Steenselen WN, Hulst JM, Olieman JF, Augustus $\mathrm{M}$, Mohd Din SH, et al. Achieving energy goals at day 4 after admission in critically ill children: Predictive for outcome? Clinical Nutrition. 2015; 34(1):115-22. [DOI:10.1016/j.clnu.2014.01.019] [PMID] 
39. Leong AY, Field CJ, Larsen BM. Nutrition support of the postoperative cardiac surgery child. Nutrition in Clinical Practice. 2013; 28(5):572-9. [DOI:10.1177/0884533613497515] [PMID]

40. Jesuit C, Dillon C, Compher C, American Society for Parenteral and Enteral Nutrition (A.S.P.E.N.) Board of Directors, Lenders CM. A.S.P.E.N. Clinical guidelines: Nutrition support of hospitalized pediatric patients with obesity. Journal of Parenteral and Enteral Nutrition. 2010; 34(1):13-20. [DOI:10.1177/0148607109354088] [PMID] [PMCID]

41. Ismail J, Bansal A, Jayashree M, Nallasamy K, Attri SV. Energy Balance in Critically III Children With Severe Sepsis Using Indirect Calorimetry: A prospective Cohort study. Journal of Pediatric Gastroenterology and Nutrition. 2019; 68(6):868-73. [DOI:10.1177/0148607109333114] [PMID]

42. Briassoulis G, Venkataraman S, Thompson AE. Energy expenditure in critically ill children. Critical Care Medicine. 2000; 28(4):1166-72. [DOI:10.1097/00003246-20000400000042] [PMID]

43. Framson CM, LeLeiko NS, Dallal GE, Roubenoff R, Snelling LK, Dwyer JT. Energy expenditure in critically ill children. Pediatric Critical Care Medicine 2007; 8(3):264-7. [DOI:10.1097/01.PCC.0000262802.81164.03] [PMID]

44. Kerklaan D, Fivez T, Mehta NM, Mesotten D, van Rosmalen $J$, Hulst JM, et al. Worldwide Survey of Nutritional Practices in PICUs. Pediatric Critical Care Medicine. 2016; 17(1):10-8. [DOI:10.1097/PCC.0000000000000542] [PMID]

45. Mehta NM, Smallwood CD, Joosten KF, Hulst JM, Tasker $\mathrm{RC}$, Duggan CP. Accuracy of a simplified equation for energy expenditure based on bedside volumetric carbon dioxide elimination measurement--a two-center study. Clinical Nutrition. 2015; 34(1):151-5. [DOI:10.1016/j. clnu.2014.02.008] [PMID] [PMCID]

46. Kerklaan D, Augustus ME, Hulst JM, van Rosmalen J, Verbruggen $\mathrm{S}$, Joosten KFM. Validation of ventilator-derived VCO2 measurements to determine energy expenditure in ventilated critically ill children. Clinical Nutrition. 2017; 36(2):452-7. [DOI:10.1016/j.clnu.2016.01.001] [PMID]

47. LA B. Pediatric nutrition handbook. Elk Grove Village, IL: American Academy of Pediatrics; 1993.

48. Preiser JC, van Zanten AR, Berger MM, Biolo G, Casaer MP, Doig GS, et al. Metabolic and nutritional support of critically ill patients: consensus and controversies. Critical Care. 2015; 19:35. [DOI:10.1186/s13054-015-07378] [PMID] [PMCID]

49. Edwards JD, Houtrow AJ, Vasilevskis EE, Rehm RS, Markovitz BP, Graham RJ, et al. Chronic conditions among children admitted to U.S. pediatric intensive care units: Their prevalence and impact on risk for mortality and prolonged length of stay. Critical Care Medicine. 2012; 40(7):2196-203. [DOI:10.1097/ CCM.0b013e31824e68cf] [PMID] [PMCID]
50. Coss-Bu JA, Hamilton-Reeves J, Patel JJ, Morris CR, Hurt RT. Protein Requirements of the Critically III Pediatric Patient. Nutrition in Clinical Practice. 2017; 32(1_suppl):128S-41S. [DOI:10.1177/0884533617693592] [PMID]

51. Hulst J, Joosten K, Zimmermann L, Hop W, van Buuren S, Büller $\mathrm{H}$, et al. Malnutrition in critically ill children: From admission to 6 months after discharge. Clinical Nutrition. 2004; 23(2):223-32. [DOI:10.1016/S0261-5614(03)00130-4]

52. Goldman HI, Freudenthal R, Holland B, Karelitz S. Clinical effects of two different levels of protein intake on low-birthweight infants. The Journal of Pediatrics. 1969; 74(6):881-9. [DOI:10.1016/S0022-3476(69)80222-2]

53. Goldman HI, Liebman OB, Freudenthal R, Reuben R. Effects of early dietary protein intake on low-birth-weight infants: Evaluation at 3 years of age. The Journal of Pediatrics. 1971; 78(1):126-9. [DOI:10.1016/S0022-3476(71)80277-9]

54. Botrán M, Lopez-Herce J, Mencia S, Urbano J, Solana MJ, Garcia A. Enteral nutrition in the critically ill child: comparison of standard and protein-enriched diets. The Journal of Pediatrics. 2011; 159(1):27-32 e1. [DOI:10.1016/j. jpeds.2011.02.001] [PMID]

55. de Betue CT, van Waardenburg DA, Deutz NE, van Eijk HM, van Goudoever JB, Luiking YC, et al. Increased protein-energy intake promotes anabolism in critically ill infants with viral bronchiolitis: A double-blind randomised controlled trial. Archives of Disease in Childhood. 2011; 96(9):817-22. [DOI: 10.1136/adc.2010.185637] [PMID] [PMCID]

56. Botrán M, Lopez-Herce J, Mencia S, Urbano J, Solana MJ, Garcia A, et al. Relationship between energy expenditure, nutritional status and clinical severity before starting enteral nutrition in critically ill children. The British Journal of Nutrition. 2011; 105(5):731-7. [DOI:10.1017/ S0007114510004162] [PMID]

57. Bechard L, Parrott JS, Mehta NM. Systematic review of the influence of energy and protein intake on protein balance in critically ill children. The Journal of Pediatrics. 2012; 161(2):333-9 e1. [DOI:10.1016/j.jpeds.2012.01.046] [PMID]

58. Keshen TH, Miller RG, Jahoor F, Jaksic T. Stable isotopic quantitation of protein metabolism and energy expenditure in neonates on- and post-extracorporeal life support. Journal of Pediatric Surgery. 1997; 32(7):958-63. [DOI:10.1016/S0022-3468(97)90377-8]

59. van Waardenburg DA, de Betue CT, Goudoever JB, Zimmermann LJ, Joosten KF. Critically ill infants benefit from early administration of protein and energy-enriched formula: a randomized controlled trial. Clinical Nutrition. 2009; 28(3):249-55. [DOI:10.1016/j.clnu.2009.03.005] [PMID]

60. Cole CR. Optimizing protein in the diets of critically ill children: Time for re-evaluation. The Journal of Pediatrics. 2011; 159(1):5-6. [DOI:10.1016/j.jpeds.2011.03.029] [PMID] 
61. Scurlock CS, Raikhelkar J, Mechanick J. Parenteral nutrition in the critically ill patient. The New England Journal of Medicine. 2010; 362(1):81; author reply 3-4. [DOI:10.1056/NEJMc0909589] [PMID]

62. Wilson B, Typpo K. Nutrition: A Primary Therapy in Pediatric Acute Respiratory Distress Syndrome. Frontiers in Pediatrics. 2016; 4:108. [DOI:10.3389/fped.2016.00108] [PMID] [PMCID]

63. Al-Saady NM, Blackmore CM, Bennett ED. High fat, low carbohydrate, enteral feeding lowers $\mathrm{PaCO} 2$ and reduces the period of ventilation in artificially ventilated patients. Intensive Care Medicine. 1989; 15(5):290-5. [DOI:10.1007/ BF00263863] [PMID]

64. Al-Dorzi HM, Aldawood AS, Tamim H, Haddad SH, Jones G, McIntyre $\mathrm{L}$, et al. Caloric intake and the fat-to-carbohydrate ratio in hypercapnic acute respiratory failure: Post-hoc analysis of the PermiT trial. Clinical Nutrition ESPEN. 2019; 29:175-82. [DOI:10.1016/j.clnesp.2018.10.012] [PMID]

65. Dao DT, Anez-Bustillos L, Cho BS, Li Z, Puder M, Gura KM. Assessment of Micronutrient Status in Critically III Children: Challenges and Opportunities. Nutrients. 2017; 9(11). [DOI:10.3390/nu9111185] [PMID] [PMCID]

66. Seear M, Lockitch G, Jacobson B, Quigley G, MacNab A. Thiamine, riboflavin, and pyridoxine deficiencies in a population of critically ill children. The Journal of Pediatrics. 1992; 121(4):533-8. [DOI:10.1016/S0022-3476(05)81140-0]

67. Calder PC. Long-chain n-3 fatty acids and inflammation: potential application in surgical and trauma patients. Brazilian Journal of Medical and Biological Research. 2003; 36(4):433-46. [DOI:10.1590/S0100-879X2003000400004] [PMID]

68. Stortz JA, Murphy TJ, Raymond SL, Mira JC, Ungaro R, Dirain $M L$, et al. Evidence for persistent immune suppression in patients who develop chronic critical illness after sepsis. Shock. 2018; 49(3):249-58. [DOI:10.1097/ SHK.0000000000000981] [PMID] [PMCID]

69. Lorenz KJ, Schallert R, Daniel V. Immunonutrition - the influence of early postoperative glutamine supplementation in enteral/parenteral nutrition on immune response, wound healing and length of hospital stay in multiple trauma patients and patients after extensive surgery. GMS Interdisciplinary Plastic and Reconstructive Surgery DGPW. 2015; 4:Doc15. [DOI:10.3205/iprs000074] [PMID] [PMCID]

70. Tao KM, Li XQ, Yang LQ, Yu WF, Lu Z, Sun YM, et al. Glutamine supplementation for critically ill adults. The Cochrane Database of Systematic Reviews. 2014; (9):CD010050. [DOI:10.1002/14651858.CD010050.pub2] [PMID] [PMCID]

71. Heyland DK, Dhaliwal R, Drover JW, Gramlich L, Dodek P, Canadian Critical Care Clinical Practice Guidelines C. Canadian clinical practice guidelines for nutrition support in mechanically ventilated, critically ill adult patients. Journal of Parenteral and Enteral Nutrition. 2003; 27(5):355-73. [D OI:10.1177/0148607103027005355] [PMID]
72. Roudi F, Zakerian M, Ranjbar G. The beneficial anti-inflammatory and anti-oxidative effects of selenium supplementation in critically III post-surgical pediatric patients. Journal of Nutrition, Fasting and Health. 2020; 8(2):75-9. [10.22038/JNFH.2019.42549.1213]

73. Roudi F, Sezavar M, Rajabi O, Safarian M, Khademi G, Nematy $M$, et al. The effects of high-dose selenium supplementation on the oxidative stress status and inflammatory markers in critically III pediatric patients after gastrointestinal surgery: A randomized clinical trial protocol study. Journal of Nutrition Fasting and Health. 2020; 8(3):159-68. [DOI:10.22038/JNFH.2020.48170.1261]

74. Roudi F, Khademi G, Ranjbar G, Rafatpanah H, Esmaily H, Nematy M. Effects of high-dose selenium supplementation on oxidative stress and inflammatory markers in critically III children after gastrointestinal surgery: A randomized clinical trial. Iranian Journal of Pediatrics. 2020; 30(4). [DOI:10.5812/ijp.102118]

75. Allingstrup $M$, Afshari A. Selenium supplementation for critically ill adults. The Cochrane Database of Systematic Reviews. 2015(7):CD003703. [DOI:10.1002/14651858. CD003703.pub3] [PMID] [PMCID]

76. Garcia de Acilu M, Leal S, Caralt B, Roca O, Sabater J, Masclans JR. The role of omega-3 polyunsaturated fatty acids in the treatment of patients with acute respiratory distress syndrome: A clinical review. BioMed Research International. 2015; 2015:653750. [DOI:10.1155/2015/653750] [PMID] [PMCID]

77. Dushianthan A, Cusack R, Burgess VA, Grocott MP, Calder P. Immunonutrition for adults with ARDS: Results from a cochrane systematic review and meta-Analysis. Respiratory Care. 2020; 65(1):99-110. [DOI:10.4187/respcare.06965] [PMID]

78. Briassoulis G, Filippou O, Hatzi E, Papassotiriou I, Hatzis T. Early enteral administration of immunonutrition in critically ill children: results of a blinded randomized controlled clinical trial. Nutrition. 2005; 21(7-8):799-807. [DOI:10.1016/j. nut.2004.12.006] [PMID]

79. Wu G, Morris SMJr. Arginine metabolism: Nitric oxide and beyond. The Biochemical Journal. 1998; 336 (Pt 1):1-17. [DOI:10.1042/bj3360001] [PMID] [PMCID]

80. Morris SM Jr. Arginine: Beyond protein. The American Journal of Clinical Nutrition. 2006; 83(2):508S-512S. [DOI:10.1093/ajcn/83.2.508S] [PMID]

81. Tsikas D, Wu G. Homoarginine, arginine, and relatives: Analysis, metabolism, transport, physiology, and pathology. Amino Acids. 2015; 47(9):1697-702. [DOI:10.1007/ s00726-015-2055-5] [PMID]

82. Gunst J, Vanhorebeek I, Thiessen SE, Van den Berghe G. Amino acid supplements in critically ill patients. Pharmacological Research. 2018; 130:127-31. [DOI:10.1016/j. phrs.2017.12.007] [PMID] 
83. Van Waardenburg DA, Jansen TC, Vos GD, Buurman WA. Hyperglycemia in children with meningococcal sepsis and septic shock: the relation between plasma levels of insulin and inflammatory mediators. The Journal of Clinical Endocrinology \& Metabolism. 2006; 91(10):3916-21.

84. Argaman Z, Young VR, Noviski N, Castillo-Rosas L, Lu $X M$, Zurakowski $D$, et al. Arginine and nitric oxide metabolism in critically ill septic pediatric patients. Critical Care Medicine. 2003; 31(2):591-7. [DOI:10.1097/01. CCM.0000050291.37714.74] [PMID]

85. Yu YM, Sheridan RL, Burke JF, Chapman TE, Tompkins RG, Young VR. Kinetics of plasma arginine and leucine in pediatric burn patients. The American Journal of Clinical Nutrition. 1996; 64(1):60-6. [DOI:10.1093/ajcn/64.1.60] [PMID]

86. Wernerman J. Clinical use of glutamine supplementation. The Journal of Nutrition. 2008; 138(10):2040S-4S. [DOI:10.1093/jn/138.10.2040S] [PMID]

87. van der Hulst RRWJ, von Meyenfeldt MF, Deutz NEP, Soeters PB, Brummer RJM, von Kreel BK, et al. Glutamine and the preservation of gut integrity. The Lancet. 1993; 341(8857):1363-5. [DOI:10.1016/0140-6736(93)90939E]

88. Ekmark L, Rooyackers O, Wernerman J, Flaring U. Plasma glutamine deficiency is associated with multiple organ failure in critically ill children. Amino Acids. 2015; 47(3):535-42. [DOI:10.1007/s00726-014-1885-x] [PMID]

89. Lang PO, Aspinall R. Can we translate vitamin D immunomodulating effect on innate and adaptive immunity to vaccine response? Nutrients. 2015; 7(3):2044-60. [DOI:10.3390/nu7032044] [PMID] [PMCID]

90. Hayes CE, Nashold FE, Spach KM, Pedersen LB. The immunological functions of the vitamin $D$ endocrine system. Cellular and Molecular Biology (Noisy-le-Grand, France). 2003; 49(2):277-300. [PMID]

91. Bischoff HA, Stahelin HB, Dick W, Akos R, Knecht M, Salis $C$, et al. Effects of vitamin $D$ and calcium supplementation on falls: A randomized controlled trial. Journal of Bone and Mineral Research. 2003; 18(2):343-51. [DOI:10.1359/ jbmr.2003.18.2.343] [PMID]

92. Pilz S, Marz W, Wellnitz B, Seelhorst U, Fahrleitner-Pammer A, Dimai HP, et al. Association of vitamin D deficiency with heart failure and sudden cardiac death in a large cross-sectional study of patients referred for coronary angiography. The Journal of Clinical Endocrinology and Metabolism. 2008; 93(10):3927-35. [DOI:10.1210/ jc.2008-0784] [PMID]

93. Zosky GR, Berry LJ, Elliot JG, James AL, Gorman S, Hart $\mathrm{PH}$. Vitamin $\mathrm{D}$ deficiency causes deficits in lung function and alters lung structure. American Journal of Respiratory and Critical Care Medicine. 2011; 183(10):1336-43. [DOI:10.1164/rccm.201010-15960C] [PMID]
94. Ebenezer K, Job V, Antonisamy B, Dawodu A, Manivachagan MN, Steinhoff $M$. Serum Vitamin D Status and Outcome among Critically III Children Admitted to the Pediatric Intensive Care Unit in South India. Indian Journal of Pediatrics. 2016; 83(2):120-5. [DOI:10.1007/ s12098-015-1833-0] [PMID]

95. Baqui AH, Williams E, El-Arifeen S, Applegate JA, Mannan I, Begum N, et al. Effect of community-based newborn care on cause-specific neonatal mortality in Sylhet district, Bangladesh: Findings of a cluster-randomized controlled trial. Journal of Perinatology. 2016; 36(1):71-6. [DOI:10.1038/jp.2015.139] [PMID]

96. Ram Jat K. Vitamin D and pneumonia in children: A case control study. Pulmonary Medicine \& Respiratory Research. 2016; 2(1):1-4. [DOI:10.24966/PMRR-0177/100004]

97. Ponnarmeni $S$, Kumar Angurana $S$, Singhi $S$, Bansal $A$, Dayal $D$, Kaur R, et al. Vitamin D deficiency in critically ill children with sepsis. Paediatrics and International Child Health. 2016; 36(1):15-21. [DOI:10.1179/204690551 5Y.0000000042] [PMID]

98. Rippel C, South M, Butt WW, Shekerdemian LS. Vitamin D status in critically ill children. Intensive Care Medicine. 2012; 38(12):2055-62. [DOI:10.1007/s00134-012-2718-6] [PMID]

99. Heyland DK, Dhaliwal R, Day AG, Muscedere J, Drover J, Suchner $U$, et al. REducing Deaths due to OXidative Stress (The REDOXS Study): Rationale and study design for a randomized trial of glutamine and antioxidant supplementation in critically-ill patients. The Proceedings of the Nutrition Society. 2006; 65(3):250-63. [DOI:10.1079/PNS2006505] [PMID]

100. Andrews PJ, Avenell A, Noble DW, Campbell MK, Battison $\mathrm{CG}$, Croal BL, et al. Randomised trial of glutamine and selenium supplemented parenteral nutrition for critically ill patients. Protocol Version 9, 19 February 2007 known as SIGNET (Scottish Intensive care Glutamine or seleNium Evaluative Trial). Trials. 2007; 8:25. [DOI:10.1186/17456215-8-25] [PMID] [PMCID] 
This Page Intentionally Left Blank 